\title{
Crohns Disease of Jejunum Masquerading as Malabsorption
}

\author{
Dr. Anil Mohan Rao. S MD ${ }^{1 *}$, Dr. Syed Sajid Hussein Shah ${ }^{2}$
}

${ }^{1}$ Assistant Professor of Pathology, ${ }^{2}$ FCPS Professor of Pathology, Faculty of Medicine, Northern Border University Arar 73222 K.S.A

\author{
DOI: $10.36348 / \mathrm{sjpm} .2020 . \mathrm{v} 05 \mathrm{i} 05.004$ \\ | Received: 01.05.2020 | Accepted: 08.05.2020 | Published: 12.05.2020 \\ *Corresponding author: Dr. Anil Mohan Rao. S MD
}

\section{Abstract}

Crohns Disease also referred to as regional enteritis is a chronic disease with waxing and waning course. This condition is associated with profound psychological and physical effect on the affected patient. The disease has diverse clinicopathological manifestations with significant attendant complications, morbidity and mortality. In this study attempt is made to address the many clinico-pathological presentations of the disease with focus on various aspects of differential diagnosis along with description of diagnostic approach by appropriate use of variousdiagnostic modalities. In addition recent pathogenetic mechanisms will be described which will having bearing and implications on therapeutic aspects of disease, that can influence the natural history and overall course of disease. This case is presented in view of its uncommon location and associated clinical manifestation.

Keywords: Crohns Disease, Pathological, Jejunum, Diagnosis, Malabsorption.

Copyright @ 2020: This is an open-access article distributed under the terms of the Creative Commons Attribution license which permits unrestricted use, distribution, and reproduction in any medium for non-commercial use (NonCommercial, or CC-BY-NC) provided the original author and sources are credited.

\section{INTRODUCTION}

Crohns Disease which is part of the Spectrum of Inflammatory Bowel Disease [IBD] occurs with relatively more frequency in females and is highly common in Western World especially in Ashkenazi Jews [1]. The average age at disease onset is in $3^{\text {rd }}$ decade with a major spike in disease in $2^{\text {nd }}$ to $3^{\text {rd }}$ decade and minor spike in $5^{\text {th }}$ decade [2]. The Incidence of Disease is about 3-20/100,000 [3] whereas Prevalence is $1.3 \%$ [4]. The disease in Asia shows more predispositions for males with an incidence of $1.37 / 100,000$ [5]. The most common site of involvement is Ileo-colonic junction in 50\% cases [6]. Common mode of presentation is Non bloody diarrhea \& Fever, followed by Abdominal pain and intestinal obstruction [7]. Crohns disease during its course can be complicated with Colonic Dysplasia and Colonic Cancer which prompts for Close follow up and effective screening [8].

\section{CASE REPORT}

A 30 year old male presented to hospital with diarrhea weight loss and fever of 3-4 months duration. A Clinical diagnosis of Malabsorption presumably due to CROHNS DISEASE OF JEJUNUM is made and a portion of Jejunum is resected and sent for
Histopathology, for further confirmation and Management.

\section{Pathological examination}

Gross Examination-Shows $15 \times 6 \times 4 \mathrm{~cm}$ portion of Jejunum, which appears to be dilated throughout and cut section shows focal area of ulceration surrounded by bile stained normal looking mucosal folds.

Microscopic Examination-Showed Transmural Chronic Inflammation and Non Caseating Epitheloid Granulomas with Giant cells in Sub mucosa and Serosa suggestive of Crohns disease of jejunum

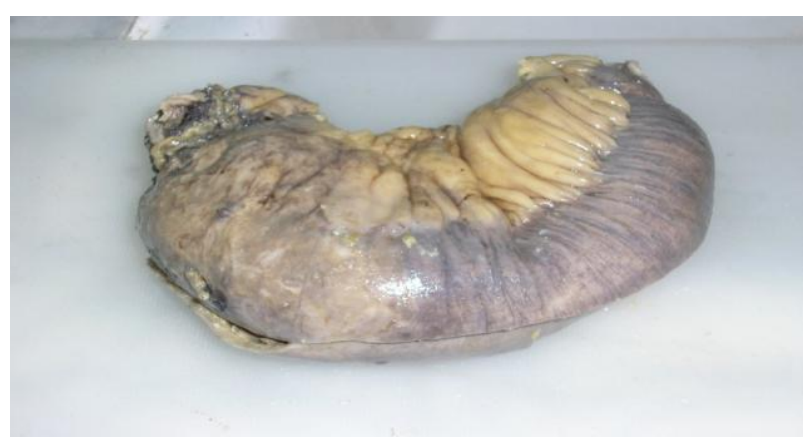

$15 \times 6 \times 4 \mathrm{~cm}$ portion of Jejunum, which appears to be dilated throughout

With Creeping Fat Appearance 


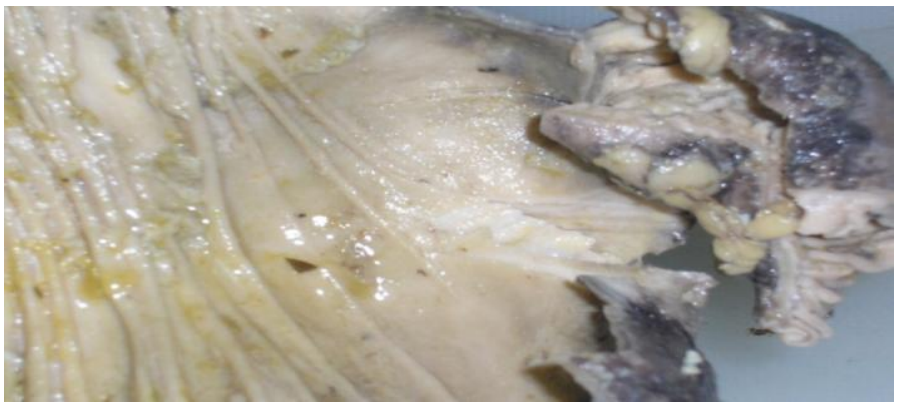

Cut section shows focal area of ulceration surrounded by bile stained normal looking mucosal folds

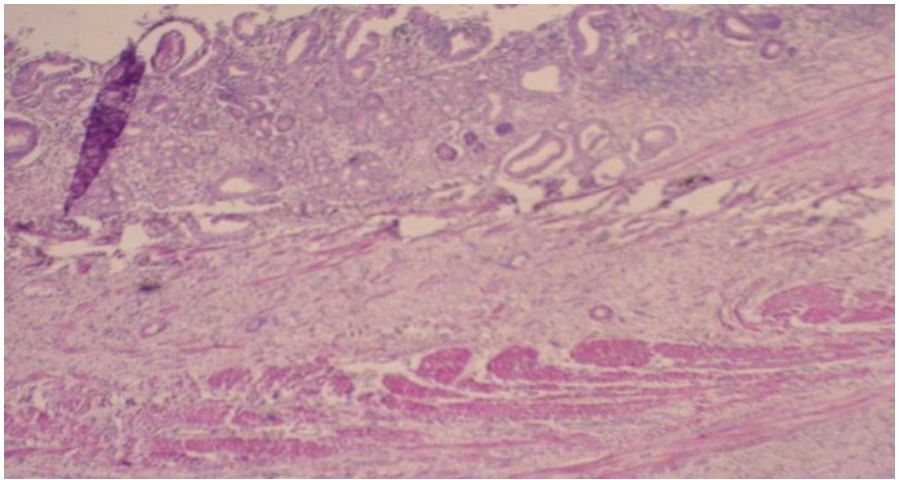

Jejunal Mucosal Chronic Inflammation

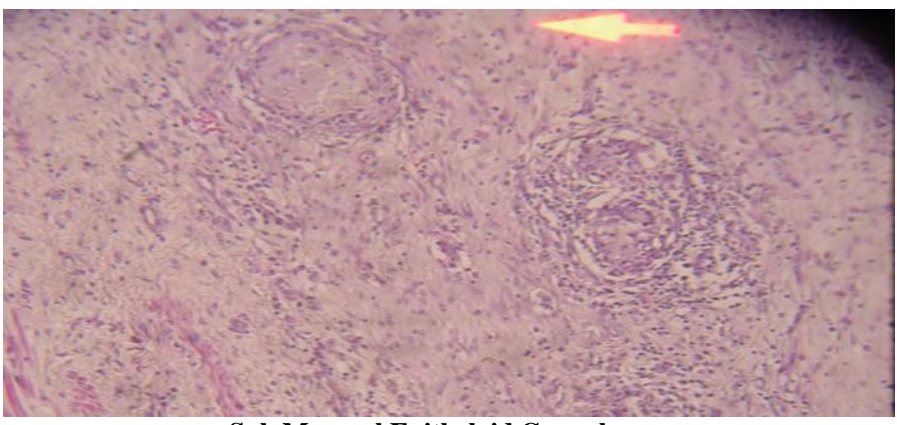

Sub Mucosal Epitheloid Granulomas

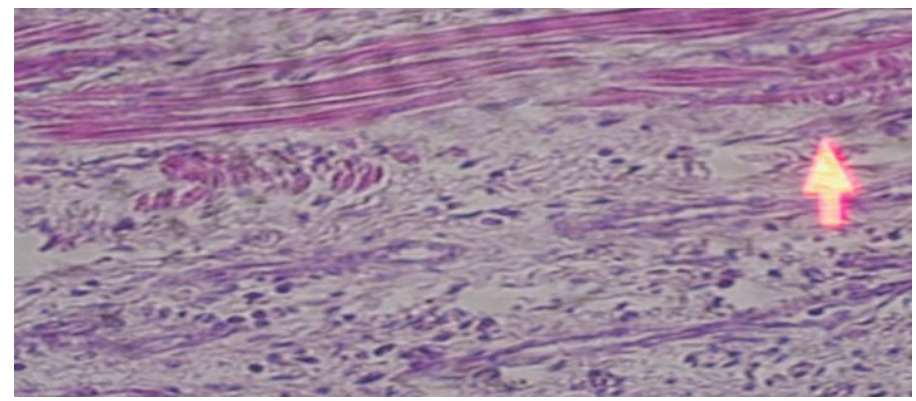

Chronic Inflammation in Muscle Layer

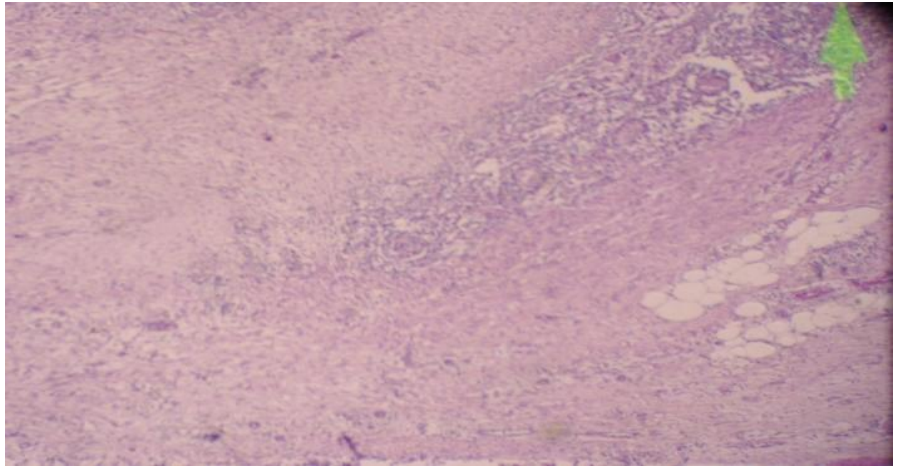

Serosal Chronic Inflammation along with Giant cells and Epitheloid Granulomas 


\section{DISCUSSION}

Crohns disease can be considered as Multifactorial disease with the role of Environmental factors in genetically predisposed individuals. Environmental Factors that can play a role in the development of disease can be gastrointestinal infections, NSAID and Antibiotic use along with oral contraceptives/Hormonal replacement therapy, especially in females [9]. The greatest risk factor however is Smoking which is proved in many studies [9]. The evidence for Genetic basis is derived from the fact that there is affected first degree relatives in upto $25 \%$ cases along with Concordance rate of upto $50 \%$ and $10 \%$ for Monozygotic twins, Dizygotic twins respectively [10]. Studies have proven the role of Single Nucleotide polymorphisms [SNP] of Protein tyrosine phosphatase non-receptor type 2 and 22 gene (PTPN2/22) in Crohns Disease by predisposition to the Mycobacterial Infection that leads to Inflammation and Apoptosis due to reduced loss of Control of $\mathrm{T}$ cell activity [11]. In addition loss of control of Mucosal Pattern recognition receptors [Toll like Receptors [TLR], NOD like receptors [NLR] due to Mutations in TLR/NODR genes has been shown to confer risk for Crohns Disease by favouring infection by commensals and inappropriate local immune activity[12]. Local Immune activation due to excess expression of TLR/NDR on Mucosal immune cells leads to increased role of IL-6 which is the hallmark of Chronic Inflammation [13]. The critical role of IL-6 is confirmed by evidence of clinical improvement in patients who were given Anti IL-6 Antibody [13]. The role of Immune modulation in Crohns Disease is shown by the fact that selective JAK-1 Inhibitor [Filgotinib] induced remission in phase- 2 clinical trials, which is due to its negative effect on $\mathrm{T}$-cell maturation and synthetic blockage of proinflammatory cytokines [IL-21 \&IFN-gamma][14]. Novel Monoclonal Antibody [Ustekinumab] which was recently approved for Clinical use has been shown to bind with P40 molecule which is a common thread for IL-12 \&IL-23, thereby ceasing the activity of these cytokines[IL-12\&IL-23] and further leads to blockage of both Th-1\&Th-17 cell types [15]. In addition therapeutic antagonists of P19 moiety of IL-23, such as risankizumab and MEDI2070 also showed good results in Phase 2 trials[16]. The concept of Autophagy and its role in Crohns Disease has been put forward, where in genetic studies showed defects in Autophagy Genes [ATG16L1, IRGM, and LRRK2], that leads to inadequate clearing of infectious particles by Lysosomes and thereby Precipitate Immune reaction[17]. The role of ER stress in bowel mucosal cells is due to genetic defects in ER stress concerned genes. ER stress prompts the development of UPR [Unfolded Protein Response] which maintains Gut Homeostasis by maintenance of Epithelial Barrier and function of Paneth cells /Secretory cells. Animal models showed lack of UPR leads to disease [18]. Grossly Crohns Disease appearance is similar throughout GIT as it can involve any portion of GIT, from Oral cavity to Anus and are prominent on mucosal $\&$ Serosal side. They can range from Perianal Fistulas[14-76\%], Skip Areas, Stictures, Penetrating Disease[Fistulas, Inflammatory Masses, Abscess]. Fistulas can be intraabdominal or perianal type and are usually associated with Strictures. Mucosal lesions are diverse and can be seen in same case. The Mucosal lesions are Apthous or Sepiginous Ulcers to Cobblestone pattern [specificlesion]. Other findings include Bowel wall thickening, Creeping Fat of involved area, Serosal prominent vessels and Exudate, Mesentry show Fibrous strands along with enlarged Lymph Nodes. Inflammatory Pseudopolyps[20\%] can be seen as Mucosal Overgrowths, of various length.

Microscopically, findings range from Non Caseating Granulomas[15-85\%] seen in all layers of Intestine, Segmental Crypt Atrophy/Distortion, Focal and Patchy Inflammation of Mucosal Epithelium [Crypts], Cryptitis with Activity [Neutrophils in superficial Epithelium], Metaplasia of Gastric type, Trans Mural Inflammation., Neuronal Changes [Hyperplasia of Submucosal Nerves [19]. Small bowel disease characteristically shows Granulomatous Lymphangitis[20]. Histologic Evidence of disease Activity and Chronicity is important in terms disease management. Indicators of Activity are Erosion, Superfical Ulceration, Cryptitis, Crypt Abscess, whereas Chronicity features are, shortened Crypts with structural distortion, Lymphoplasmacytic infiltrate at lower end of Crypts, Paneth cell Metaplasia below the level of Splenic Flexure and Pyloric Gland Metaplasia in Colon, Ileum[21].

Differentiation of Various conditions on Microscopy such as Chronic Inflammation due to infections such as Tuberculosis of Bowel, Amoebic Colitis, Pseudotuberculosis. Ischemic Colitis. Diverticulitis, Lymphocytic Colitis. Drug Induced Colitis. Ulcerative Colitis should be made based on careful histologic examination, with possible Clinical Correlation [21].

Acute Infectious Colitis usually shows Neutrophilic Infiltrate in Lamina propria and is selflimited, whereas Chronic Infectious Colitis, like Intestinal Tuberculosis, Amoebic Colitis, Pseudo tuberculosis warrants the identification/growth of Organisms in Biopsy, Stool or by serological exam and clinical correlation [21]. Ischemic Colitis shows superficial injury along with reduced Crypts and Fibrotic Lamina Propria, which are absent in Crohns Disease [21]. Diverticultis is usually seen in areas of Diverticulosis. Lymphocytic Colitis in contast to Crohns Disease is normal on Endoscopy but Microscopically shows Focal lesions similar to Crohns Disease [21]. Drug Induced Colitis [NSAIDS, Mycophenolate] changes are clearly notable by presence of Apoptotic Cryptsand Solitary Crypt damage [21]. Clinical [Endoscopic Pattern, Symptoms] and 
Pathological criteria to distinguish Crohns Disease from Ulcerative Colitis Includes Epitheloid Granuloma [seen away from Mucosal Injury], Transmural Chronic Inflammation and absence of Mucin depletion, along with Positive Staining of BCL-2 by Immunohistochemical study [22].The Clinical Features of Crohns Disease differs according to site of involvement in GIT. Common symptoms include Diarrhea [bloody/non bloody], Abdominal Pain, Fever. Small Bowel involvement manifests as Various Nutritional Deficiencies due to impaired absorption. Symptoms related to complications, bowel obstruction due to stricture, Fever due to Abscess, or local symptoms of Fistula can be noted. In about Half of cases Ileo-colonic junction is involved, $1 / 3^{\text {rd }}$ of cases there is small bowel involvement, $1 / 5^{\text {th }}$ times its in Colon and $1 / 4^{\text {th }}$ times its Perianal disease [23]. The Extra Intestinal Manifestations [Arthritis, Erythema Nodosum, Uveitis, Primary Sclerosing Cholangitis, Nephrolithiasis, Deep Vein Thrombosis] are related to immune phenomena of Crohns disease [23]. The Diagnosis of Crohns disease is achieved by close correlation of Clinical Features, Radiological, Endoscopic and Pathological Findings. Diagnostic Imaging modalities such as, CTE, MRE [computed tomography enterography, Magnetic resonance enterography] helps to observe the Bowel wall, Mucosa and complications of disease [Fistulas]. Imaging has replaced Barium studies in evaluation and identification of disease. MRE is relatively safe [24]. Endoscopic Visualization with Mucosal Biopsy are vital in recognition and follow of disease. For recognition of likely disease, minimum of 2 tissue samples are taken from 5 various sites that include, last part of Ileum, Rectum, with both diseased and normal looking mucosa, submitted in separate containers.

In follow up Endoscopy, Identifiable diseased areas are selected for Pathological study. In case of Pancolitis, 33 tissues are sampled at every $10 \mathrm{~cm}$ level from cecum to rectum to screen for possible dysplasia. For distal colon involvement tissue sample is taken for study at every $5 \mathrm{~cm}$ level to identify dyplasia and Colorectal Cancer [25]. The long term potential complication of Crohns disease is development of Dysplasia and Colonic Cancer, which is due to accumulation of various genetic insults in patients with long standing Colitis. These Genetic alterations include premature loss of P53, and late loss of K-ras and APC function, which contribute to carcinogenesis by increasing cytokine mediated DNA damage, increased activation of NF-kb, Neovascularization and Tumoral growth[26]. The risk factors associated with development of Colorectal Cancer in Patients with long standing Colitis are 1.early onset of colitis [less than 15 years] $2.1 / 3^{\text {rd }}$ to $1 / 2$ involved Colonic mucosa 3 . Increased disease severity and duration of more than 710 years 4.Patients with Crohns disease with Primary Sclerosing Cholangitis 5. Stricturing Disease [27]. According to ASGE [American Society of
Gastrointestinal Endoscopy] yearly surveillance with Endoscopy is advised for patients at greater risk [Active Colitis, Stricturs, H/o Dysplasia, Primary Sclerosing Cholangitis, Family History], Surveillance every 3 years for those with 2 negative surveillance and no evidence of Colitis and Surveillance every 5 years for those with No recommendation [28]. The recommendations of SCENIC says that 2 categories of Dysplasia is identified Visible Dysplasia and Invisible Dysplasia. For Visible Dysplasia, complete resection followed by surveillance is advised, whereas those with Non resectable Visible Dysplasia Colectomy is advised. Patients with Invisible Dysplasia are referred to Chromoendoscopy by IBD specialist, who takes personalized decisions [29].

\section{CONCLUSION}

Crohns disease is characterized by gradual but progressive course which warrants therapeutic and diagnostic intervention to improve the clinicopathological features. This can be achieved by proper immunotherapy, which modulates immune system to control the disease severity. Complications of disease are treated by Surgery. Long term surveillance and follow up of the disease is mandatory to detect earlier pathological changes [dysplasia] which canbe managed appropriately as mentioned by various therapeutic procedures.

\section{REFERENCES}

1. Ng, S. C., Bernstein, C. N., Vatn, M. H., Lakatos, P. L., Loftus, E. V., Tysk, C., ... \& Colombel, J. F. (2013). Geographical variability and environmental risk factors in inflammatory bowel disease. Gut, 62(4), 630-649.

2. Cheifetz, A. S. (2013). Management of active Crohn disease. Jama, 309(20), 2150-2158.

3. Molodecky, N. A., Soon, S., Rabi, D. M., Ghali, W. A., Ferris, M., Chernoff, G., ... \& Kaplan, G. G. (2012). Increasing incidence and prevalence of the inflammatory bowel diseases with time, based on systematic review. Gastroenterology, 142(1), 4654.

4. Dahlhamer, J. M., Zammitti, E. P., Ward, B. W., Wheaton, A. G., \& Croft, J. B. (2016). Prevalence of inflammatory bowel disease among adults aged $\geq$ 18 years-United States, 2015. Morbidity and Mortality Weekly Report, 65(42), 1166-1169.

5. Ooi, C. J., Hilmi, I., Makharia, G. K., Gibson, P. R., Fock, K. M., Ahuja, V., ... \& Leung, W. K. (2016). The Asia Pacific Consensus Statements on Crohn's Disease Part 2: definition, diagnosis and epidemiology.

6. Cheifetz, A. S. (2013). Management of active Crohn disease. Jama, 309(20), 2150-2158.

7. Obaseki, D. E., \& Forae, G. D. (2014). Clinicopathological features of inflammatory bowel disease in Benin City, Nigeria. International Journal of Advanced Medical and Health Research, 1(1), 16. 
8. Dulai, P. S., Sandborn, W. J., \& Gupta, S. (2016). Colorectal cancer and dysplasia in inflammatory bowel disease: a review of disease epidemiology, pathophysiology, and management. Cancer prevention research, 9(12), 887-894.

9. Abegunde, A. T., Muhammad, B. H., Bhatti, O., \& Ali, T. (2016). Environmental risk factors for inflammatory bowel diseases: Evidence based literature review. World journal of gastroenterology, 22(27), 6296.

10. Cleynen, I., Boucher, G., Jostins, L., Schumm, L. P., Zeissig, S., Ahmad, T., ... \& Brant, S. R. (2016). Inherited determinants of Crohn's disease and ulcerative colitis phenotypes: a genetic association study. The Lancet, 387(10014), 156-167.

11. Sharp, R. C., Beg, S. A., \& Naser, S. A. (2018). Role of PTPN2/22 polymorphisms in pathophysiology of Crohn's disease. World journal of gastroenterology, 24(6), 657.

12. Ahluwalia, B., Magnusson, M. K., \& Öhman, L. (2017). Mucosal immune system of the gastrointestinal tract: maintaining balance between the good and the bad. Scandinavian journal of gastroenterology, 52(11), 1185-1193.

13. Danese, S., Vermeire, S., Hellstern, P., Panaccione, R., Rogler, G., Fraser, G., ... \& Cataldi, F. (2019). Randomised trial and open-label extension study of an anti-interleukin-6 antibody in Crohn's disease (ANDANTE I and II). Gut, 68(1), 40-48.

14. Vermeire, S., Schreiber, S., Petryka, R., Kuehbacher, T., Hebuterne, X., Roblin, X., ... \& Sike, R. (2017). Clinical remission in patients with moderate-to-severe Crohn's disease treated with filgotinib (the FITZROY study): results from a phase 2, double-blind, randomised, placebocontrolled trial. The Lancet, 389(10066), 266-275.

15. Feagan, B. G., Sandborn, W. J., Gasink, C., Jacobstein, D., Lang, Y., Friedman, J. R., ... \& Adedokun, O. J. (2016). Ustekinumab as induction and maintenance therapy for Crohn's disease. New England Journal of Medicine, 375(20), 1946-1960.

16. Sands, B. E., Chen, J., Feagan, B. G., Penney, M., Rees, W. A., Danese, S., ... \& Li, J. (2017). Efficacy and safety of MEDI2070, an antibody against interleukin 23, in patients with moderate to severe Crohn's disease: a phase 2a study. Gastroenterology, 153(1), 77-86.

17. Levine, B., \& Kroemer, G. (2008). Autophagy in the pathogenesis of disease. Cell, 132(1), 27-42.

18. Walter, P., \& Ron, D. (2011). The unfolded protein response: from stress pathway to homeostatic regulation. Science, 334(6059), 1081-1086.
19. Geboes, K. (2003). Histopathology of Crohn's disease and ulcerative colitis. Inflammatory bowel disease, 4, 210-28.

20. Cui, Y., Lu, S. Y., Xu, J., Peng, Y. S., Miao, Q., Wang, X. Q., ... \& Ran, Z. H. (2019). Microscopic features of small bowel mucosa of patients with Crohn's disease. BMC gastroenterology, 19(1), 18.

21. Lee, H., Westerhoff, M., Shen, B., \& Liu, X. (2016). Clinical aspects of idiopathic inflammatory bowel disease: a review for pathologists. Archives of pathology \& laboratory medicine, 140(5), 413428.

22. The Importance of Clinicopathological Features for Differentiation between Crohn's Disease And Ulcerative ColitisInt. J. Adv. Res. 5(2), 139-146

23. Feuerstein, J. D., \& Cheifetz, A. S. (2017, July). Crohn disease: epidemiology, diagnosis, and management. In Mayo Clinic Proceedings (Vol. 92, No. 7, pp. 1088-1103). Elsevier.

24. Dambha, F., Tanner, J., \& Carroll, N. (2014). Diagnostic imaging in Crohn's disease: what is the new gold standard?. Best Practice \& Research Clinical Gastroenterology, 28(3), 421-436.

25. Shergill, A. K., Lightdale, J. R., Bruining, D. H., Acosta, R. D., Chandrasekhara, V., Chathadi, K. V., .. \& Fisher, D. A. (2015). The role of endoscopy in inflammatory bowel disease. Gastrointestinal Endoscopy, 81(5), 11011121.

26. Robles, A. I., Traverso, G., Zhang, M., Roberts, N. J., Khan, M. A., Joseph, C., ... \& Ke, X. (2016). Whole-exome sequencing analyses of inflammatory bowel Disease- ${ }^{-}$Associated colorectal cancers. Gastroenterology, 150(4), 931943.

27. Dulai, P. S., Sandborn, W. J., \& Gupta, S. (2016). Colorectal cancer and dysplasia in inflammatory bowel disease: a review of disease epidemiology, pathophysiology, and management. Cancer prevention research, 9(12), 887-894.

28. Desai, D., \& Desai, N. (2014). Colorectal cancer surveillance in inflammatory bowel disease: A critical analysis. World journal of gastrointestinal endoscopy, 6(11), 541.

29. Laine, L., Kaltenbach, T., Barkun, A., McQuaid, K. R., Subramanian, V., Soetikno, R., ... \& Kiesslich, R. (2015). SCENIC international consensus statement on surveillance and management of dysplasia in inflammatory bowel disease. Gastroenterology, 148(3), 639-651. 